\section{Monitoring and Controlling Ebb-and- flow Subirrigation with Soil Moisture Sensors}

\author{
Rhuanito Soranz Ferrarezi ${ }^{1}$ and Marc W. van Iersel \\ Department of Horticulture, University of Georgia, 1111 Miller Plant \\ Science Building, Athens, GA 30602
}

Roberto Testezlaf

School of Agricultural Engineering, University of Campinas, 501 Candido Rondon Street, Campinas, SP 13083-875, Brazil

Additional index words. automation, capacitance sensor, Hibiscus acetosella 'Panama Red', irrigation, substrate volumetric water content

\begin{abstract}
Subirrigation can reduce water loss and nutrient runoff from greenhouses, because used nutrient solution is collected and recirculated. Capacitance moisture sensors can monitor substrate volumetric water content $(\theta)$ and control subirrigation based on minimum $\theta$ thresholds, providing an alternative to timers. Our objectives were to automate an ebb-andflow subirrigation system using capacitance moisture sensors, monitor moisture dynamics within the containers, and determine the effect of five $\theta$ thresholds $(0.10,0.18,0.26,0.34$, or $0.42 \mathrm{~m}^{3} \cdot \mathrm{m}^{-3}$ ) on hibiscus (Hibiscus acetosella Welw. ex Hiern.) 'Panama Red' (PP20,121) growth. Subirrigation was monitored using capacitance sensors connected to a multiplexer and a data logger and controlled using a relay driver connected to submersible pumps. As the substrate $\theta$ dropped below the thresholds, irrigation was turned on for 3 min followed by 3-min drainage. Capacitance sensors effectively controlled subirrigation by irrigating only when substrate $\theta$ dropped below the thresholds. Each irrigation cycle resulted in a rapid increase in substrate $\theta$, from 0.10 to $\approx 0.33 \mathrm{~m}^{3} \cdot \mathrm{m}^{-3}$ with the $0.10-\mathrm{m}^{3} \cdot \mathrm{m}^{-3}$ irrigation threshold vs. an increase in $\theta$ from 0.42 to $0.49 \mathrm{~m}^{3} \cdot \mathrm{m}^{-3}$ with the $0.42-\mathrm{m}^{3} \cdot \mathrm{m}^{-3}$ irrigation threshold. Less nutrient solution was used in the lower $\theta$ threshold treatments, indicating that sensor control can reduce water and thus fertilizer use in subirrigation systems. The water dynamics showed that the bottom part of the pots was saturated after irrigation with $\theta$ decreasing quickly after an irrigation event, presumably because of drainage. However, the water movement among substrate layers was slow with the $0.10-\mathrm{m}^{3} \cdot \mathrm{m}^{-3}$ irrigation threshold with water reaching the upper layer 5.5 to $20 \mathrm{~h}$ after irrigation. The $0.10-\mathrm{m}^{3} \cdot \mathrm{m}^{-3} \mathrm{\theta}$ threshold resulted in $81 \%$ fewer irrigations and $70 \%$ less nutrient solution use compared with the $0.42-\mathrm{m}^{3} \cdot \mathrm{m}^{-3} \theta$ threshold. However, the $0.10-\mathrm{m}^{3} \cdot \mathrm{m}^{-3} \theta$ threshold also reduced hibiscus shoot height by $30 \%$, shoot dry weight $74 \%$, and compactness by $63 \%$ compared with the $0.42-\mathrm{m}^{3} \cdot \mathrm{m}^{-3} \theta$ threshold. Our results indicate that soil moisture sensors can be used to control subirrigation based on plant water use and substrate water and to manipulate plant growth, thus providing a tool to improve control over plant quality in subirrigation systems.
\end{abstract}

Greenhouse production of container plants typically involves the intensive use of water and water-soluble fertilizers. To prevent drought stress, water is commonly applied in excess, resulting in leaching and runoff. This can contaminate surface and groundwater with nutrients or pesticide residues (Dumroese et al., 2006). Governmental

Received for publication 19 Nov. 2014. Accepted for publication 24 Nov. 2014.

Funding for this research was provided by the American Floral Endowment and USDA-NIFASCRI award no. 2009-51181-05768.

We thank the Capes Foundation (Ministry of Education, Brazil) for scholarships to the first author as a research scholar and postdoctoral researcher at the University of Georgia (Proc. BEX 1390/10-4 and BEX 2620/13-8) and Fafard Inc. for substrate donation. Technical help was provided by Sue K. Dove and Karina Aparecida dos Santos Soranz.

${ }^{1}$ To whom reprint requests should be addressed; e-mail rhuanito@terra.com.br. regulations concerning nutrient solution disposal are becoming increasingly strict around the world. Conservative irrigation practices can be implemented to help growers comply with environmental regulations while reducing production costs (Lumis et al., 2000; Majsztrik et al., 2011). Recirculating irrigation systems, including subirrigation, prevent leaching and runoff because excess nutrient solution is collected and stored for later use (Schmal et al., 2011). Subirrigation can also reduce overall water and nutrient use (Majsztrik et al., 2011). For example, Dumroese et al. (2006) found that subirrigation requires $56 \%$ less water than overhead irrigation. However, subirrigation is typically controlled using timers to irrigate based on a pre-determined schedule. Further refinement of subirrigation scheduling practices that apply water based on plant demand would enable growers to more efficiently produce high-quality plants, conserving both water and fertilizer.
Capacitance substrate moisture sensors have been successfully used to monitor and control drip irrigation based on target $\theta$ thresholds for containerized plants grown in greenhouses (Burnett and van Iersel, 2008; Garland et al., 2012; Nemali and van Iersel, 2006; van Iersel et al., 2010; Zhen et al., 2014) as well as outdoor nurseries (Bayer et al., 2013). Sensor-controlled drip irrigation can precisely maintain substrate $\theta$ close to set values and thereby minimize water use and reduce nutrient leaching (Bayer et al., 2013; Nemali and van Iersel, 2006). Sensor-based automation could also allow growers to have better control over subirrigation. Soil moisture sensors allow real-time $\theta$ monitoring, and $\theta$ thresholds for triggering irrigation can easily be adjusted to meet particular crop watering requirements or in response to changing environmental conditions.

Soil moisture sensors can be connected to data loggers to automatically measure $\theta$ and control irrigation. A limitation is that a basic knowledge of data logger programming and wiring is required (Miralles-Crespo and van Iersel, 2011). However, newly developed hardware and software, specifically designed for greenhouse and nursery irrigation, is expected to make sensor-based irrigation available for growers of ornamental crops in the near future (Kohanbash et al., 2013). Prototype systems have been trialed in commercial facilities and can benefit both growers and domestic users (Chappell et al., 2013; Lea-Cox et al., 2013). Recent research has demonstrated that sensor control can be implemented using low-cost, open-source microcontrollers for small systems (Ferrarezi et al., 2015), whereas extensive wireless networks have been used at large production sites (Chappell et al., 2013; van Iersel et al., 2013). Thus, scale-appropriate solutions for automating subirrigation systems exist for many growers. Subirrigation systems have been successfully automated based on substrate water content using tensiometers (Montesano et al., 2010; Rouphael et al., 2006) as well as capacitance moisture sensors (Ferrarezi et al., 2014).

We assessed the effects of different $\theta$ thresholds for controlling irrigation on $\theta$ dynamics and plant growth in a sensor-controlled subirrigation system. Our objectives were: 1) to automate a subirrigation system using capacitance-type soil moisture sensors to monitor and control substrate $\theta ; 2$ ) to evaluate short-term substrate $\theta$ dynamics in subirrigated pots; and 3 ) to quantify the effect of different $\theta$ thresholds on hibiscus 'Panama Red' growth. Hibiscus was chosen as the model crop because of previous work showing its responsiveness to substrate $\theta$ (Bayer et al., 2013).

\section{Materials and Methods}

Plant material and growing conditions. The experiment was conducted in a glasscovered greenhouse at the University of Georgia, Athens, GA, from 15 Sept. to 28 Oct. 2010. Three hundred fifty 30-d-old rooted hibiscus 
'Panama Red' cuttings were transplanted into $15-\mathrm{cm}$ diameter $\times 12-\mathrm{cm}$ high pots filled with a peat-perlite substrate (Fafard 1P; Fafard, Agawam, MA). All plants were pinched at 8 $\mathrm{d}$ after transplanting (DAT) to a shoot height of $20 \mathrm{~cm}$ to encourage branching. At 14 DAT, all plants were sprayed with $0.4 \mathrm{~g} \cdot \mathrm{L}^{-1}$ of $8.5 \%$ acetamiprid (TriStar; Cleary Chemicals LLC, Dayton, NJ) to exterminate caterpillars. Plants were grown on 10 ebb-and-flow benches with $1.52 \mathrm{~m}$ length $\times 0.91 \mathrm{~m}$ width $\times 4 \mathrm{~cm}$ height (MidWest GroMaster, St. Charles, IL) covered with commercial-grade weed cloth (Weed FreePro Fabric; DuPont, Wilmington, DE). A separate 70-L tank and submersible pump (NK-2; Little Giant, Oklahoma City, OK) were used for each bench (Fig. 1A).

Plants were irrigated as needed with a $20 \mathrm{~N}-4.4 \mathrm{P}-16.6 \mathrm{~K}$ nutrient solution (Peters Professional 20-10-20 Peat-Lite Special; Everris, Marysville, OH) diluted to 100 $\mathrm{mg} \cdot \mathrm{L}^{-1}$ nitrogen. Nutrient solution electrical conductivity (EC) and $\mathrm{pH}$ were measured at the beginning of the experiment and three times a week thereafter using an $\mathrm{EC} / \mathrm{pH}$ meter (Checkmate 90; Corning, Corning, $\mathrm{NY}$ ); $\mathrm{EC}$ and $\mathrm{pH}$ remained close to 0.59 $\mathrm{dS} \cdot \mathrm{m}^{-1}$ and 6.0 throughout the experiment. The nutrient solution was replenished as needed and the volume added was recorded to determine water use.

Environmental conditions inside the greenhouse were monitored using a temperature and relative humidity sensor (HMP50; Vaisala, Woburn, MA) and a photosynthetic photon flux $(P P F)$ sensor (QSO-Sun; Apogee Instruments, Logan, UT) connected to a data logger (CR10X; Campbell Scientific, Logan, UT). Readings were taken every $20 \mathrm{~min}$ and daily minimums, maximums, and averages were recorded. The vapor pressure deficit (VPD) was calculated from the saturated and actual air vapor pressure using the air temperature and relative humidity data. Daily minimum and maximum values for temperatures were $18.9 \pm 2.4$ and $30.9 \pm 3.6^{\circ} \mathrm{C}$ and for relative humidity $39.7 \% \pm 18.3 \%$ and $79.6 \% \pm 8.8 \%$ (mean $\pm \mathrm{SD}$ ). Average VPD was $1.00 \pm 0.37 \mathrm{kPa}$ and daily maximum $P P F$ was $1165 \pm 159 \mu \mathrm{mol} \cdot \mathrm{m}^{-2} \cdot \mathrm{d}^{-1}$.

Automated system for monitoring and controlling subirrigation and treatments. Three capacitance moisture sensors (EC-5; Decagon Devices, Pullman, WA) were inserted diagonally into the upper half of the substrate of three randomly selected pots on each of the 10 benches (Fig. 1B). These 30 moisture sensors were connected to a multiplexer (AM416; Campbell Scientific) and data logger (CR10X; Campbell Scientific) (Fig. 1A). The data logger excited the sensors with $2.5 \mathrm{~V}$ direct current and measured the voltage output (V) every $30 \mathrm{~min}$, then converted this value to $\theta$, and stored the average $\theta$ for each bench every $2 \mathrm{~h}$. We followed Nemali et al. (2007) guidelines to determine a substrate-specific seven-point calibration $\left(\theta=1.886 \times \mathrm{V}-0.5624, R^{2}=0.95\right)$ for the peat:perlite substrate used in this study. Measured $\theta$ values were compared with pre-set thresholds $(0.10,0.18,0.26,0.34$, and 0.42 $\mathrm{m}^{3} \cdot \mathrm{m}^{-3}$ ). When the average $\theta$ for a bench dropped below the threshold, the corresponding submersible pump was turned on for $3 \mathrm{~min}$ using a relay driver (SDM-CD16AC; Campbell Scientific) (Fig. 1A), applying $48 \mathrm{~L}$ of nutrient solution to the bench, resulting in a water height of $\approx 3 \mathrm{~cm}$. Subsequent drainage of the fertilizer solution back into the tank took $\approx 3 \mathrm{~min}$, so the duration of each irrigation event was $\approx 6$ min.

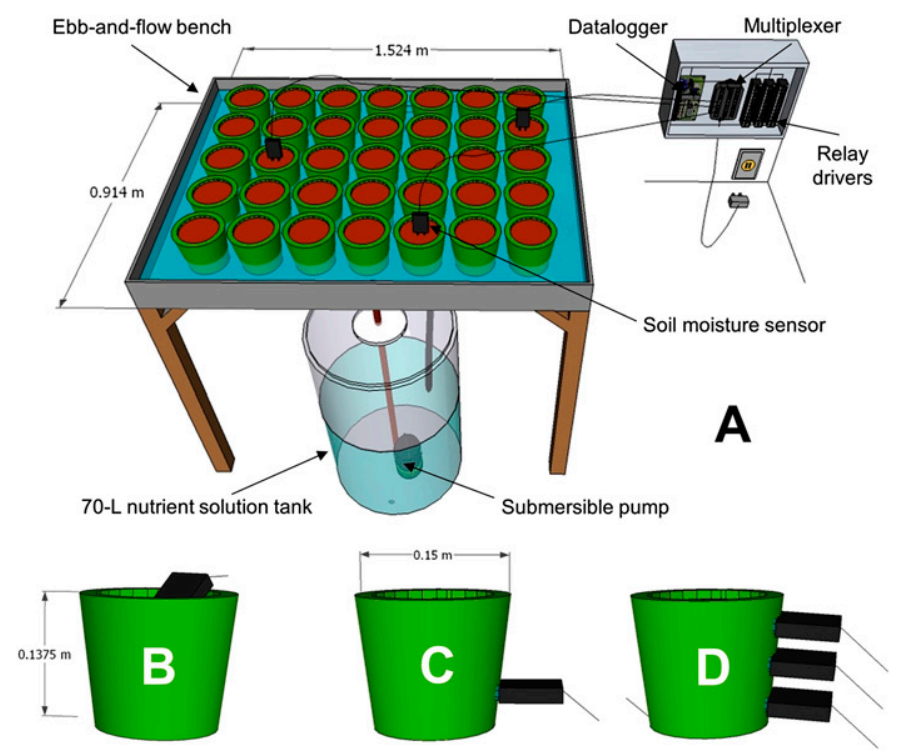

Fig. 1. Schematic view of an automated ebb-and-flow subirrigation bench with soil moisture sensors, data logger, multiplexer, relay drivers, 70-L nutrient solution tank, and submersible pump (A), control sensors inserted diagonally from the top of the pots $(\mathbf{B})$, sensors to monitor volumetric water content $(\theta)$ dynamics inserted horizontally in the bottom of pots (C), and sensors to look at vertical $\theta$ gradients within pots inserted horizontally in the bottom, middle, and top (D). Figure by Antonio Carlos Ferreira Filho.

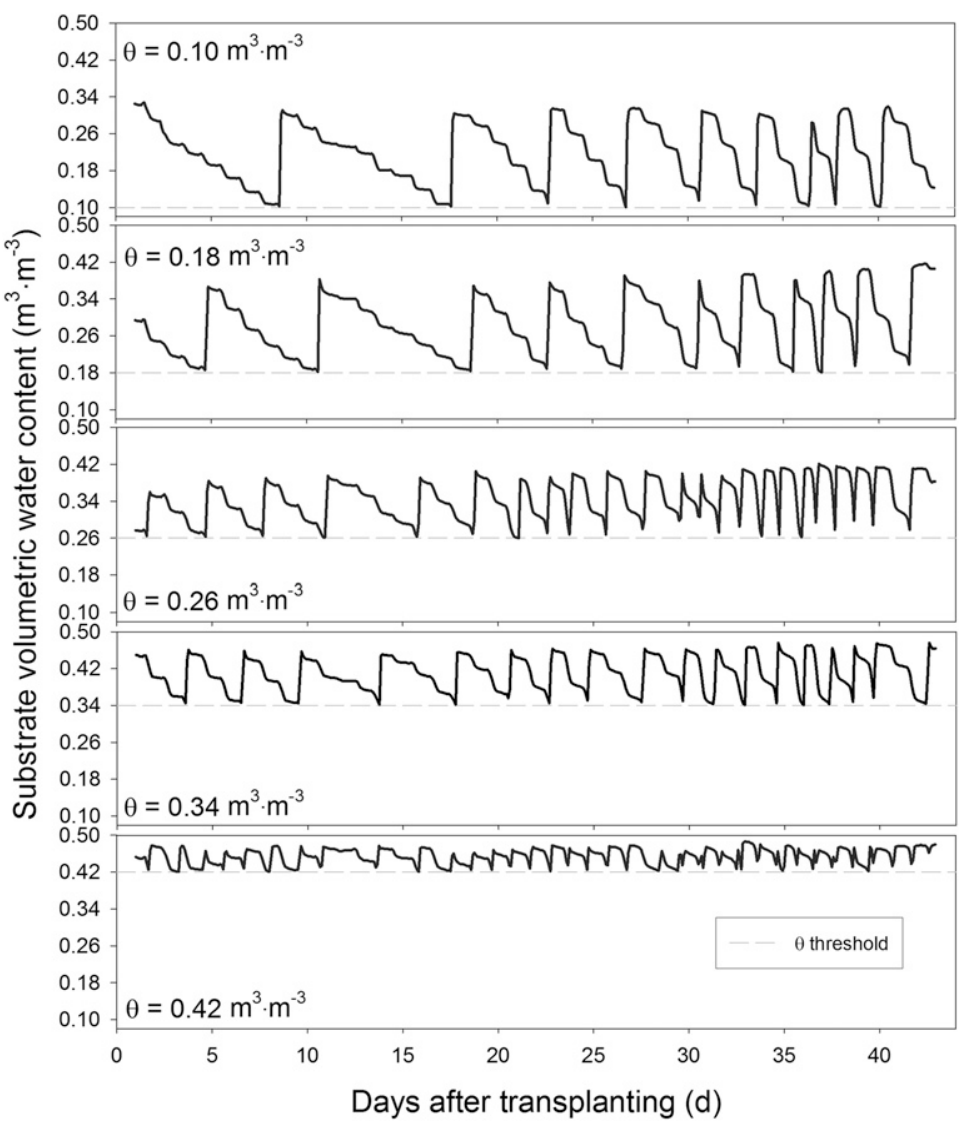

Fig. 2. Substrate volumetric water content $(\theta)$ of subirrigated containers with hibiscus 'Panama Red' Dashed horizontal lines indicate the $\theta$ at which irrigation was triggered. It appears as if irrigation is at times triggered before the irrigation $\theta$ threshold was reached. That is the result of showing $2-\mathrm{h}$ averages, whereas irrigation decisions were made based on instantaneous measurements. 
To monitor substrate $\theta$ dynamics, 30 additional EC-5 sensors were connected to a multiplexer (AM416; Campbell Scientific) and data logger (CR10X; Campbell Scientific). These sensors measured substrate $\theta$, as described previously, every $5 \mathrm{~s}$ and recorded average readings every $1 \mathrm{~min}$. From 13 to 23 DAT, three sensors were inserted horizontally into the bottom half of three randomly selected pots on each bench (Fig. 1C). To better understand the $\theta$ dynamics in the bottom substrate layer, the hourly change in $\theta$ was calculated from these data. From 24 to 43 DAT (end of the experiment), these 30 sensors were inserted horizontally into the upper, middle, and bottom thirds of a single pot per bench to examine vertical $\theta$ gradients within the pots (Fig. 1D).

Data collection. Shoot height (substrate surface to shoot tip) of 10 plants per bench and the shoot dry weight of four plants per bench were measured weekly on randomly selected plants. Pots with sensors were used for shoot height but not for shoot dry weight to avoid the need for sensor repositioning. During the sampling for shoot dry weight, plants were cut at the substrate level and dried in a forced-air drying oven at $80{ }^{\circ} \mathrm{C}$ for $5 \mathrm{~d}$. Compactness was calculated as shoot dry weight/shoot height. All plants on a particular bench were repositioned weekly to avoid border effects and the risk of uneven plant growth resulting from mutual shading. The last plants were harvested after $43 \mathrm{~d}$, when they had reached a salable size.

Experimental design and statistical analysis. The experimental design was completely randomized with five $\theta$ irrigation thresholds and two replications. The experimental unit was one ebb-and-flow bench with 35 plants at the start of the study. The number of plants decreased over time, because four plants were harvested every week for dry weight measurements. To determine treatment and time effects on shoot height and dry weight and compactness, a quadratic model, including an interaction term, was used: $\mathrm{Y}=\mathrm{a}_{0}$ $+\left(a_{1} \times\right.$ DAT $)+\left(a_{2} \times \theta\right)+\left(a_{3} \times\right.$ DAT $\left.\times \theta\right)+\left(a_{4}\right.$ $\left.\times \mathrm{DAT}^{2}\right)+\left(\mathrm{a}_{5} \times \theta^{2}\right)$, where $\mathrm{Y}=\log ($ height $)$, $\log$ (dry weight) or $\log$ (compactness), $\theta$ is the irrigation threshold, and $\mathrm{a}_{0}, \ldots, \mathrm{a}_{5}$ are regression coefficients. The relationship between $P P F$ and the rate of decrease in $\theta$ at 15 and 16 DAT was tested with a similar model, but not including quadratic components. Significance levels $\leq 0.05$ were considered statistically significant. Non-significant components in the regression equation were eliminated using stepwise selection (Proc REG, SAS 9.2; SAS Institute, Cary, NC).

\section{Results and Discussion}

Irrigation control. The automation worked properly and irrigation was triggered as needed. In all treatments, substrate $\theta$ increased rapidly during irrigation and then decreased in a stepwise pattern over time (Fig. 2). The stepwise pattern is the result of greater water use during the day than at night (van Iersel et al., 2011). Water content increased more in treatments with lower $\theta$ threshold, by $\approx 0.23 \mathrm{~m}^{3} \cdot \mathrm{m}^{-3}$ (from 0.10 to $0.33 \mathrm{~m}^{3} \cdot \mathrm{m}^{-3}$ ) with the $0.10-\mathrm{m}^{3} \cdot \mathrm{m}^{-3}$ threshold, but only $0.07 \mathrm{~m}^{3} \cdot \mathrm{m}^{-3}$ ( 0.42 to 0.49 $\mathrm{m}^{3} \cdot \mathrm{m}^{-3}$ ) with the $0.42-\mathrm{m}^{3} \cdot \mathrm{m}^{-3}$ threshold (Fig. $2)$. Irrigation resulted in large increases in substrate $\theta$ at low $\theta$ thresholds, because the drier substrate was able to absorb more water. The maintenance of substrate $\theta$ within a narrow range, which has been reported with automated drip irrigation (Bayer et al., 2013; Nemali and van Iersel, 2006; van Iersel et al., 2010), may be difficult to achieve in sensor-controlled subirrigation systems, because the amount of water absorbed by the substrate during flooding is not controlled (Ferrarezi et al., 2014). Minimizing the increase in $\theta$ after irrigation and better control over $\theta$ can be achieved by limiting the duration of flooding (Gent and McAvoy, 2011) or by restricting the height of the nutrient solution on the ebb-and-flow bench (R.S. Ferrarezi, M.W. van Iersel, and R. Testezlaf, unpublished data).

The irrigation frequency increased over time in all treatments (Fig. 2), likely as a result of plant growth and the resultant increase in transpirational water use. Similar responses have been observed in drip-irrigated hibiscus 'Panama Red' (Bayer et al., 2013) and other crops (e.g., Nemali and van Iersel, 2006; van Iersel et al., 2010).
The number of irrigation events increased exponentially from nine to 59 (Fig. $3 \mathrm{~A})$ and the total volume of nutrient solution used increased linearly from 59 to 209 L/bench (Fig. 3B) with increasing $\theta$ thresholds. Increasing the $\theta$ threshold from 0.26 to $0.42 \mathrm{~m}^{3} \cdot \mathrm{m}^{-3}$ more than doubled the number of irrigation events and almost doubled nutrient solution use. Thus, water and fertilizer use can be reduced by growing plants at lower $\theta$ thresholds. Similar results were reported in studies using sensor-controlled drip irrigation (Bayer et al., 2013; Nemali and van Iersel, 2006; van Iersel et al., 2010; Zhen et al., 2014) and subirrigation (Ferrarezi et al., 2014).

Substrate $\theta$ dynamics. The $0.10-\mathrm{m}^{3} \cdot \mathrm{m}^{-3}$ treatment was irrigated only once from 18 to 23 DAT, whereas the 0.18-, 0.26-, 0.34-, and $0.42-\mathrm{m}^{3} \cdot \mathrm{m}^{-3}$ treatments were irrigated two, three, four, and eight times, respectively, as is evident from the sharp peaks in $\theta$ in the bottom half of the substrate (Fig. 4, left). Irrigation caused the $\theta$ to spike to 0.7 to 0.9 $\mathrm{m}^{3} \cdot \mathrm{m}^{-3}$ followed by a rapid decline in $\theta$ after irrigation. This rapid decline was more pronounced with lower $\theta$ thresholds and indicates either water leaching from the pots or water redistribution within the pots. However, because the irrigation system was closed, any leachate from the pots did not result in runoff.

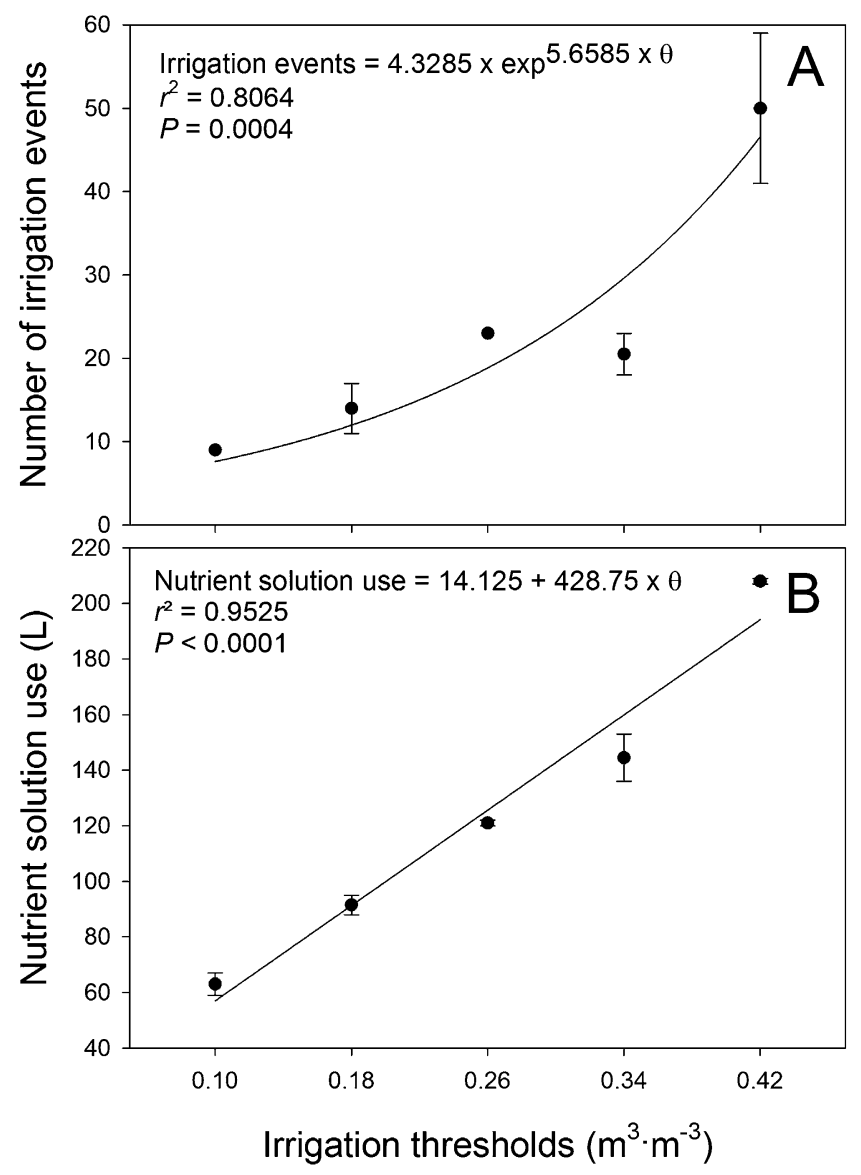

Fig. 3. Number of irrigation events (A) and volume of nutrient solution used (B) during a 43-d growing period. Hibiscus 'Panama Red' plants were subirrigated when the substrate volumetric water content $(\theta)$ dropped below specific thresholds. Error bars indicate SE. 


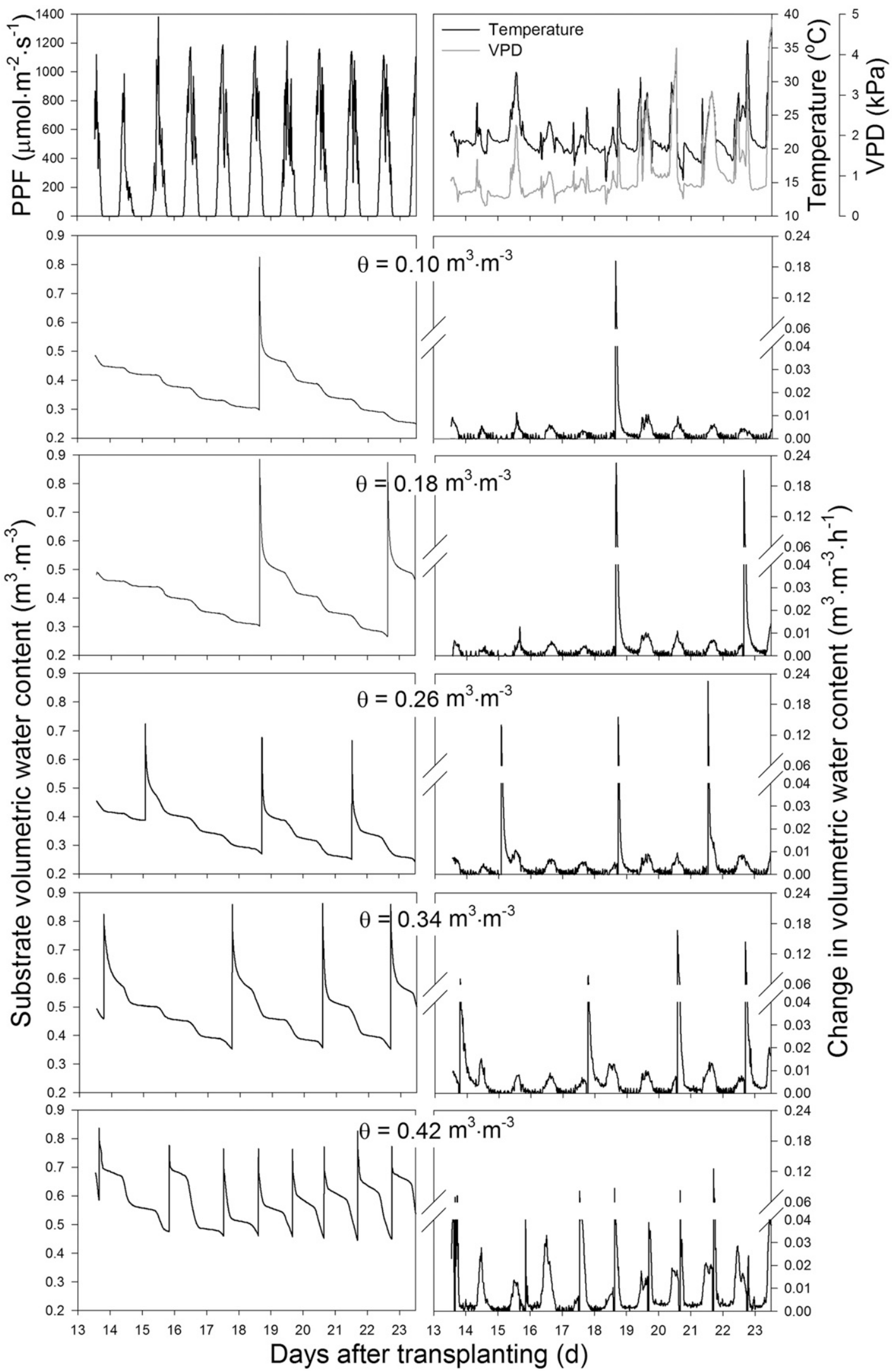

Fig. 4. Substrate volumetric water content ( $\theta$, left) and change in $\theta$ (right) over time as measured in the bottom half of containers with hibiscus 'Panama Red'. Irrigation resulted in a very rapid increase in $\theta$ followed by a rapid decrease. For clarity, the change in $\theta$ as the result of irrigation is not shown, because this resulted in large, negative values. The sharp peaks in the change of $\theta$ indicate a rapid decrease in $\theta$ immediately after irrigation, either as a result of leaching or redistribution of water within the pot. 
Dynamics in $\theta$ are especially evident when looking at the rate of change in $\theta$ (Fig. 4, right). The rate of change in $\theta$ spikes immediately after irrigation events. This indicates a rapid decrease in $\theta$ and is indicative of leaching. There also are clear diurnal patterns in the change in $\theta$, typically peaking around solar noon. These diurnal patterns were likely the result of changes in evapotranspiration rates caused by temporal variations in environmental conditions (Fig. 4, top). Bayer et al. (2013) reported that the daily water use of hibiscus was strongly dependent on the daily light integral. Our results show that the relationship between water use and light level holds on shorter time scales as well. Using the data from the $0.42-\mathrm{m}^{3} \cdot \mathrm{m}^{-3} \theta$ threshold for 15 and 16 DAT, when there was no irrigation during the day, we found a strong correlation between $P P F$ and the rate of change in substrate $\theta$. However, this correlation differed between the $2 \mathrm{~d}$ (significant $\theta \times$ DAT interaction; Fig. 5), indicating that water use was not only determined by instantaneous $P P F$. The higher water use on 16 DAT may be the

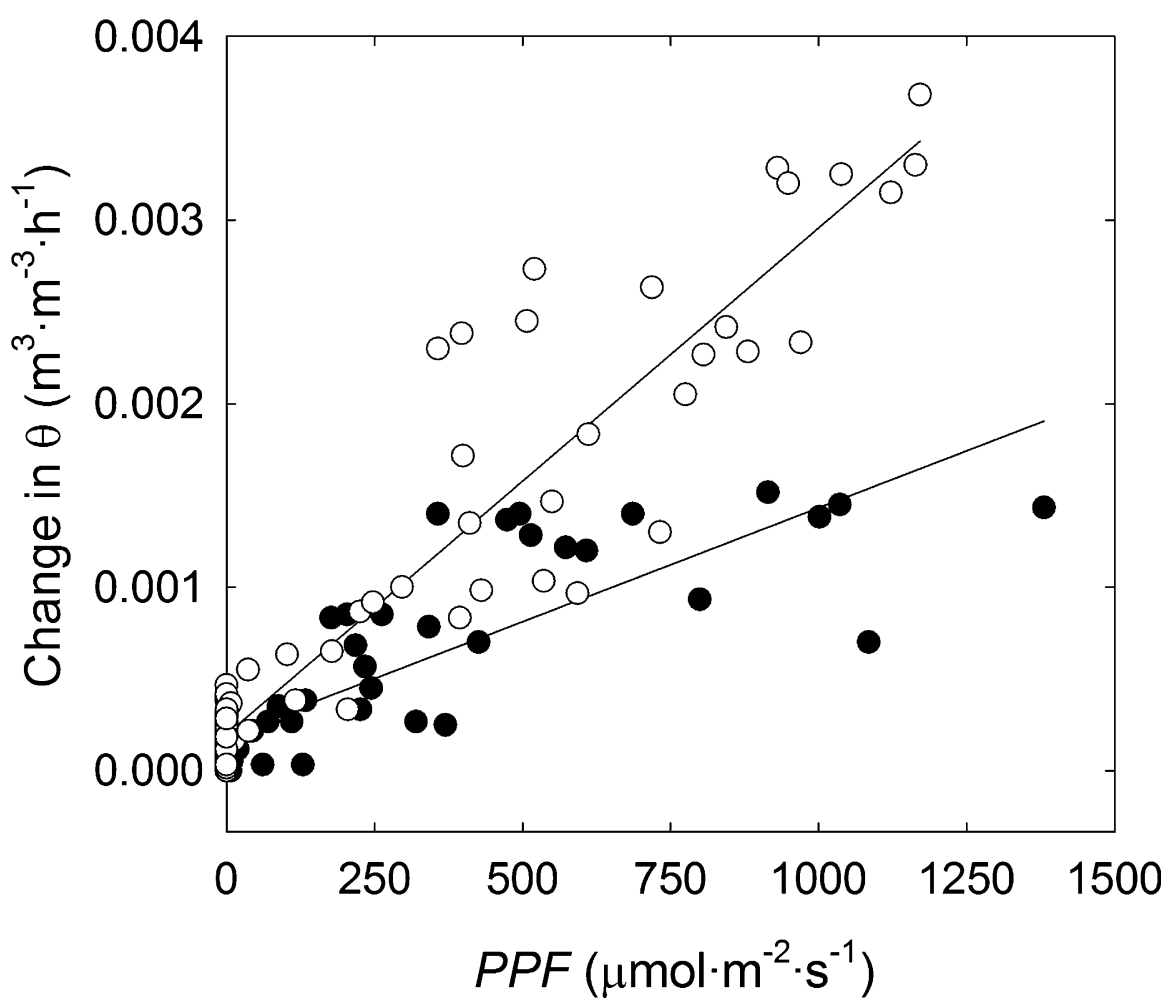

Fig. 5. The change in volumetric water content $(\theta)$ vs. photosynthetically photon flux $(P P F)$. Data are from one experimental unit with hibiscus 'Panama Red' that was subirrigated when the $\theta$ dropped below $0.42 \mathrm{~m}^{3} \cdot \mathrm{m}^{-3}$. Data are for $15(\bullet)$ and $16(\mathrm{O}) \mathrm{d}$ after transplanting (DAT). Plants were watered on the evening of 15 DAT. Data from the irrigation period and subsequent drainage are not included in the graph. The change in $\theta$, a proxy for plant water use, was affected by both $P P F\left(P<0.0001\right.$, partial $R^{2}=$ $0.74)$ and the $P P F \times$ day interaction $\left(P<0.0001\right.$, partial $\left.R^{2}=0.09\right)$.

result of irrigation in the evening of 15 DAT, increasing $\theta$ and potentially increasing plant water use or evaporation from the substrate surface. The difference in the rate of change in substrate $\theta$ between Days 15 and 16 likely was not the result of different environmental conditions between these $2 \mathrm{~d}$ (Fig. 5), because the rate of change in $\theta$ on these $2 d$ was similar in other treatments.

Vertical $\theta$ gradients were observed in both treatments with a low and high $\theta$ threshold (Fig. 6). Such gradients occur in subirrigated containers because water is absorbed by the lower part of the substrate and moves upward as a result of capillary action (Gent and McAvoy, 2011; Kent and Reed, 1996; Martinetti et al., 2008; Montesano et al., 2010; Morvant et al., 1997). The substrate $\theta$ ranged from 0.1 to 0.7 at the low and from 0.4 to $0.9 \mathrm{~m}^{3} \cdot \mathrm{m}^{-3}$ at the high $\theta$ threshold (Fig. 6). With the $0.42-\mathrm{m}^{3} \cdot \mathrm{m}^{-3}$ irrigation threshold, substrate $\theta$ increased quickly in all three substrate layers after irrigation, indicating rapid redistribution of the water within the substrate (Fig. 6, right). However, with the $0.10 \theta \mathrm{m}^{3} \cdot \mathrm{m}^{-3}$ irrigation threshold, the substrate $\theta$ increased quickly in the middle and bottom layers, but more slowly in the top layer of the substrate. This is especially evident during 33 through 41 DAT, when it took 5.5 to $20 \mathrm{~h}$ for the top substrate layer to reach its maximum $\theta$ (Fig. 6). This slow movement of water to the top layer of the substrate is likely the result of low hydraulic conductivity of soilless substrates at low $\theta$ (O'Meara et al., 2014).

Because substrate $\theta$ is spatially variable, determining the ideal measurement location is an important factor in sensor-controlled subirrigation. Measurements made near the surface may not be representative of the actual moisture available to the plants, because most root growth occurs in the middle and bottom substrate layers (Kent and Reed, 1996; Martinetti et al., 2008; Montesano et al., 2010; Morvant et al., 1997). We recommend that sensors be placed in the bottom half of the container, when feasible.

Plant growth and morphology. Shoot height, shoot dry weight, and compactness increased $(P<0.0001)$ with increasing $\theta$

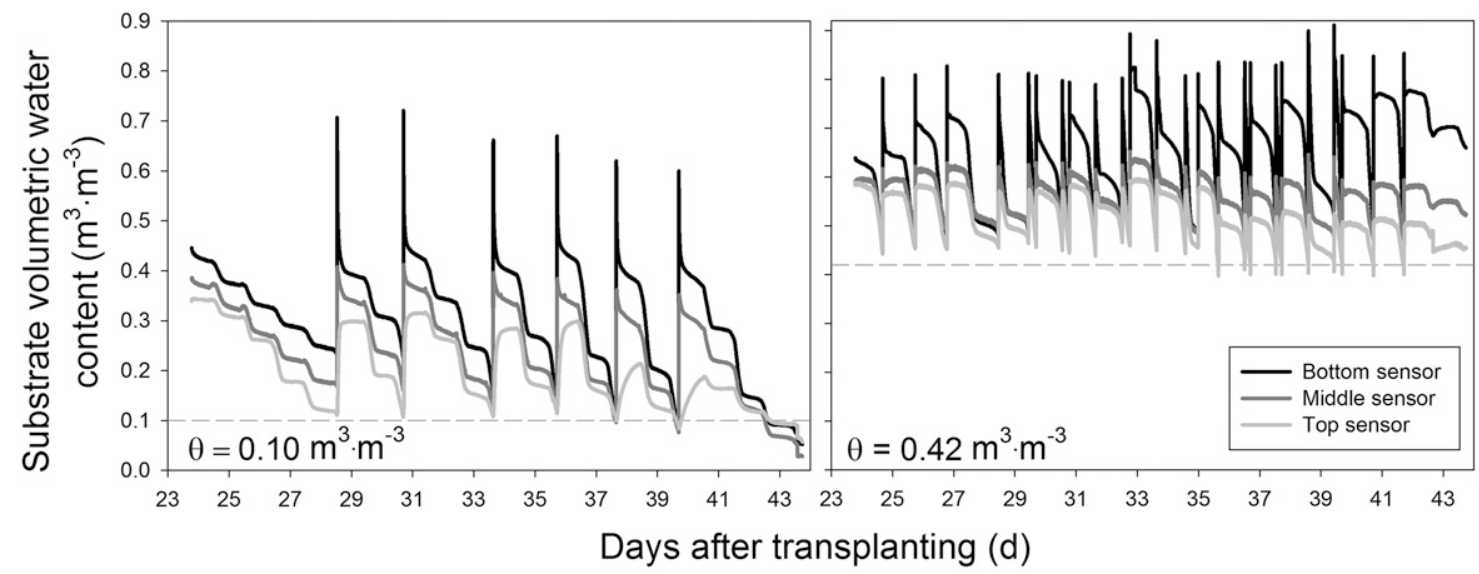

Fig. 6. Substrate volumetric water content $(\theta)$ measured at three positions (bottom, middle, and top layers of the substrate) in one container with hibiscus 'Panama Red' and $\theta$ thresholds of 0.10 (left) and $0.42 \mathrm{~m}^{3} \cdot \mathrm{m}^{-3}$ (right). 
thresholds and this effect became more pronounced over time (Fig. 7). At harvest, height increased $43 \%$ (from 56 to $80 \mathrm{~cm}$ ) as the irrigation threshold increased from 0.10 to $0.42 \mathrm{~m}^{3} \cdot \mathrm{m}^{-3}$, whereas shoot dry weight increased $290 \%$ (1.30 to $5.07 \mathrm{~g} /$ plant) with increasing $\theta$ thresholds. These results are in agreement with Bayer et al. (2013), who found similar responses in hibiscus 'Panama Red' using sensor-based drip irrigation. Most of the variability in shoot height, shoot dry weight, and compactness could be explained based on plant age (DAT), but the $\theta$ threshold and $\theta$ threshold by plant-age interactions were significant as well (Table 1; Fig. 7). The main effect of $\theta$ was not significant, likely because plant size was similar in all treatments at the beginning of the study with differences among treatments increasing over time. Because higher $\theta$ thresholds resulted in greater water use (Fig. 3B) and the plants were irrigated with nutrient solution, increased rates of water use also led to increased fertilization applications with the higher $\theta$ threshold treatments. It is therefore impossible to distinguish the influence of substrate $\theta$ from fertilizer effects on plant growth and morphology. Both factors may have contributed to the observed responses. However, multiple previous studies have demonstrated that higher $\theta$ increases plant growth in sensor-controlled drip irrigation systems, regardless of whether plants are fertilized using fertilizer solution (Burnett and van Iersel, 2008; Garland et al., 2012; van Iersel et al., 2010) or controlled-release fertilizer (Alem, 2014; Zhen et al., 2014).

Compactness is a measure of shoot density and an indicator of plant quality (Bayer et al., 2013; van Iersel and Nemali, 2004). At the final harvest, compactness increased from 2.3 to $6.3 \mathrm{~g} \cdot \mathrm{m}^{-1}(174 \%)$ as the $\theta$ threshold increased from 0.10 to $0.42 \mathrm{~m}^{3} \cdot \mathrm{m}^{-3}$. This increase in compactness occurred despite a $43 \%$ increase in shoot height over the same range of $\theta$ thresholds. However, shoot dry weight increased much more than shoot height $(290 \%)$, resulting in increased compactness at higher $\theta$ thresholds. This is indicative of better branching of the plants at higher $\theta$ thresholds. These results are similar to those of Bayer et al. (2013), who found that compactness of drip-irrigated hibiscus 'Panama Red' was positively correlated with $\theta$ threshold. Higher $\theta$ thresholds also increased shoot dry weight, number of leaves, number of branches, shoot height, and total leaf area of subirrigated salvia (Salvia splendens Sell ex Roem. \& Schult.) 'Vista Red' (Ferrarezi et al., 2014), whereas van Iersel and Nemali (2004) described similar responses in marigold (Tagetes patula L.). Thus, there is a common response among different species that low $\theta$ results in shorter but not more compact plants.

Marketable plants were produced at irrigation thresholds of 0.34 and $0.42 \mathrm{~m}^{3} \cdot \mathrm{m}^{-3}$. However, the $0.34-\mathrm{m}^{3} \cdot \mathrm{m}^{-3}$ treatment used $30 \%$ less nutrient solution than $0.42 \mathrm{~m}^{3} \cdot \mathrm{m}^{-3}$. The fact that plants irrigated at a threshold of $0.42 \mathrm{~m}^{3} \cdot \mathrm{m}^{-3}$ were bigger suggests that it may be possible to produce plants faster at this

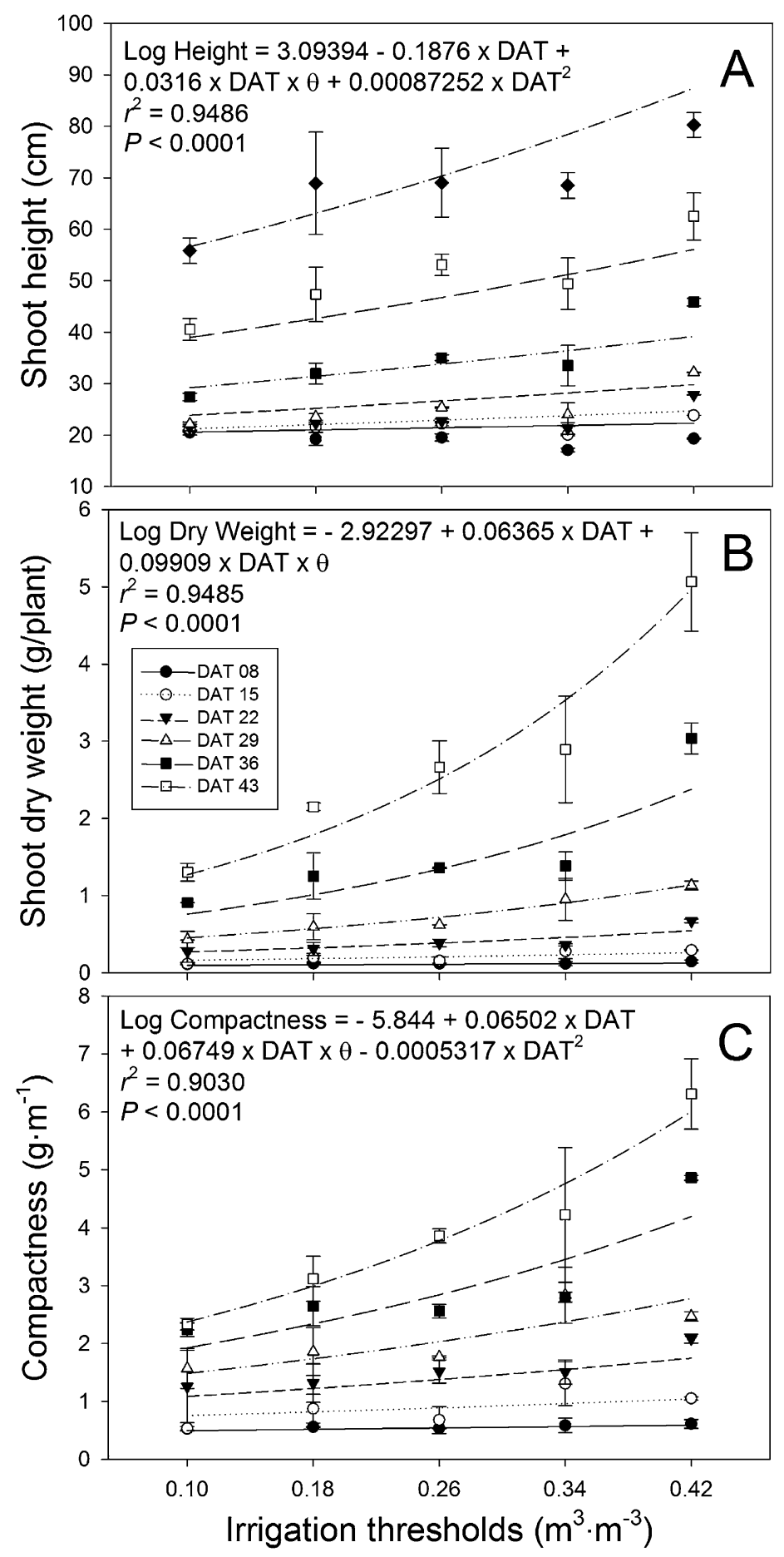

Fig. 7. Shoot height (A), shoot dry weight (B), and compactness (C) of hibiscus 'Panama Red' subirrigated when the substrate volumetric water content $(\theta)$ dropped below specific thresholds during a 43 $\mathrm{d}$ growing period. Error bars indicate SE.

higher threshold. A shorter production period would also reduce nutrient solution use. Sensor-controlled irrigation can also be used to limit plant growth by temporarily imposing a controlled water deficit. This method was successfully used to control poinsettia (Euphorbia pulcherrima Willd. ex Klotzsch) height using a sensor-controlled drip irrigation system (Alem, 2014). Because low $\theta$ thresholds decrease the height of subirrigated plants as well, adjusting the $\theta$ threshold of subirrigated plants can also be used to control elongation. However, this approach likely will be more difficult with subirrigation than with drip irrigation, because substrate $\theta$ cannot be controlled with the same precision in subirrigation systems.

Gent and McAvoy (2011) developed partial saturation ebb-and-flow watering (PSEFW). Using a pitched floor and unidirectional water flow, PSEFW rapidly delivers and removes water from flood floors. The PSEFW is an alternative method to control substrate $\theta$ in a subirrigation system. The use 
Table 1. Partial $R^{2}$ analysis of the effects of plant age (DAT, days after transplanting) and the threshold substrate water content for irrigation $(\theta)$ on shoot height, shoot dry weight, and compactness of subirrigated hibiscus 'Panama Red'.

\begin{tabular}{llcl}
\hline & Shoot ht & $\begin{array}{c}\text { Shoot dry wt } \\
\text { Partial } R^{2}\end{array}$ & Compactness \\
\hline DAT & $0.8391^{* *}$ & $0.8723^{* *}$ & $0.8100^{* *}$ \\
DAT $^{2}$ & $0.0579^{* *}$ & NS & $0.0008^{*}$ \\
DAT $\times \theta$ & $0.0516^{* *}$ & $0.0761^{* *}$ & $0.0852^{* *}$ \\
Total $R^{2}$ & 0.9486 & 0.9484 & 0.9030 \\
\hline
\end{tabular}

${ }^{\mathrm{z}}$ There was no significant main effect of $\theta$ on plant morphology.

NS, *, ** Nonsignificant or significant at $P<0.05$ or $P<0.001$, respectively.

of PSEFW restricts the amount of water absorbed by the substrate resulting in lower substrate $\theta$ and reduces water and fertilizer use and plant growth as compared with a standard flood floor (Gent and McAvoy, 2011). Thus, some of the effects of PSEFW and capacitance sensor-controlled subirrigation on crop production are similar.

\section{Conclusions}

Soil moisture sensors can be used to both monitor substrate $\theta$ and automatically control irrigation in subirrigation systems. However, fluctuations in substrate $\theta$ are much greater in sensor-controlled subirrigation than in drip systems, because the amount of water absorbed by the substrate cannot be controlled. There were distinct vertical gradients in substrate $\theta$ and sensor placement is thus an important consideration. Because most root growth, and as a result water uptake, occurs in the lower/middle part of the substrate, we recommend that sensors be placed in the bottom half of the substrate. Shoot height, dry weight, and compactness increased with increasing $\theta$ thresholds. Hence, growers can potentially adjust the $\theta$ threshold during a production cycle to manipulate plant growth, giving them a new tool to improve crop quality.

\section{Literature Cited}

Alem, P.O. 2014. Irrigation, fertilization, and nonchemical plant growth regulation in greenhouse production. PhD diss., Univ. Georgia, Athens, GA.

Bayer, A., I. Mahbub, M. Chappell, J. Ruter, and M.W. van Iersel. 2013. Water use and growth of Hibiscus acetosella 'Panama Red' grown with a soil moisture sensor-controlled irrigation system. HortScience 48:980-987.

Burnett, S.E. and M.W. van Iersel. 2008. Morphology and irrigation efficiency of Gaura lindheimeri grown with capacitance sensor-controlled irrigation. HortScience 43:1555-1560.

Chappell, M., S.K. Dove, M.W. van Iersel, P.A. Thomas, and J. Ruter. 2013. Implementation of wireless sensor networks for irrigation control in three container nurseries. HortTechnology 23:747-753.

Dumroese, R.K., J.R. Pinto, D.F. Jacobs, A.S Davis, and B. Horiuchi. 2006. Subirrigation reduces water use, nitrogen loss, and moss growth in a container nursery. Nat. Plants J. 7:253.

Ferrarezi, R.S., S.K. Dove, and M.W. van Iersel. 2015. An automated system for monitoring soil moisture and controlling irrigation using lowcost open-source microcontrollers. HortTechnology 25:110-118.

Ferrarezi, R.S., M.W. van Iersel, and R. Testezlaf. 2014. Subirrigation automated by capacitance sensors for salvia production. Horticultura Brasileira 32:314-320.

Garland, K.F., S.E. Burnett, M.E. Day, and M.W. van Iersel. 2012. Influence of substrate water content and daily light integral on photosynthesis, water use efficiency, and morphology of Heuchera americana. J. Amer. Soc. Hort. Sci. 137:57-67.

Gent, M.P.N. and R.J. McAvoy. 2011. Water and nutrient uptake and use efficiency with partial saturation ebb and flow watering. HortScience 46:791-798.

Kent, M.W. and D.W. Reed. 1996. Nitrogen nutrition of New Guinea impatiens 'Barbados' and spathiphyllum 'Petite' in a subirrigation system. J. Amer. Soc. Hort. Sci. 121:816-819.

Kohanbash, D., G. Kantor, T. Martin, and L. Crawford. 2013. Wireless sensor network design for monitoring and irrigation control: User-centric hardware and software development. HortTechnology 23:725-734.

Lea-Cox, J.D., W.L. Bauerle, M.W. van Iersel, G.F. Kantor, T.L. Bauerle, E. Lichtenberg, D.M. King, and L. Crawford. 2013. Advancing wireless sensor networks for irrigation management of ornamental crops: An overview. HortTechnology 23:717-724.

Lumis, G., P. Purvis, and L. Taurins. 2000. Flood irrigation of container-grown Euonymus and Thuja as affected by fertilizer rate and substrate. J. Environ. Hort. 18:13-17.

Majsztrik, J.C., A.G. Ristvey, and J.D. Lea-Cox. 2011. Water and nutrient management in the production of container-grown ornamentals. Hort. Rev. 38:253-297.

Martinetti, L., A. Ferrante, and E. Quattrini. 2008. Effect of drip or subirrigation on growth and yield of Solanum melongena L. in closed systems with salty water. Res. J. Biol. Sci. 3:467-474.

Miralles-Crespo, J. and M.W. van Iersel. 2011. A calibrated time domain transmissometry soil moisture sensor can be used for precise automated irrigation of container-grown plants. HortScience 46:889-894.

Montesano, F., A. Parente, and P. Santamaria. 2010. Closed cycle subirrigation with low concentration nutrient solution can be used for soilless tomato production in saline conditions. Sci. Hort. 124:338-344.

Morvant, J.K., J.M. Dole, and E. Allen. 1997. Irrigation systems alter distribution of roots, soluble salts, nitrogen, and $\mathrm{pH}$ in the root medium. HortTechnology 7:156-160.

Nemali, K.S., F. Montesano, S.K. Dove, and M.W. van Iersel. 2007. Calibration and performance of moisture sensors in soilless substrates: ECH2O and Theta probes. Sci. Hort. 112:227-234.

Nemali, K.S. and M.W. van Iersel. 2006. An automated system for controlling drought stress and irrigation in potted plants. Sci. Hort. 110:292-297.

O’Meara, L., M.R. Chappell, and M.W. van Iersel. 2014. Water use of Hydrangea macrophylla and Gardenia jasminoides in response to a gradually drying substrate. HortScience 49:493-498.

Rouphael, Y., M. Cardarelli, E. Rea, A. Battistelli, and G. Colla. 2006. Comparison of the subirrigation and drip-irrigation systems for greenhouse zucchini squash production using saline and non-saline nutrient solutions. Agr. Water Mgt. 82:99-117.

Schmal, J.L., R.K. Dumroese, A.S. Davis, J.R. Pinto, and D.F. Jacobs. 2011. Subirrigation for production of native plants in nurseriesConcepts, current knowledge, and implementation. Nat. Plants J. 12:81-93.

van Iersel, M.W., M. Chappell, and J.D. Lea-Cox. 2013. Sensors for improved efficiency of irrigation in greenhouse and nursery production. HortTechnology 23:735-746.

van Iersel, M.W., S. Dove, and S.E. Burnett. 2011. The use of soil moisture probes for improved uniformity and irrigation control in greenhouses. Acta Hort. 893:1049-1056.

van Iersel, M.W., S. Dove, J.-G. Kang, and S.E. Burnett. 2010. Growth and water use of petunia as affected by substrate water content and daily light integral. HortScience 45:277-282.

van Iersel, M.W. and K.S. Nemali. 2004. Drought stress can produce small but not compact marigolds. HortScience 39:1298-1301.

Zhen, S., S.E. Burnett, M.E. Day, and M.W. van Iersel. 2014. Effects of substrate water content on morphology and physiology of rosemary, Canadian columbine, and Cheddar pink. HortScience 49:486-492. 